\title{
Synergism between a foldase and an unfoldase: reciprocal dependence between the thioredoxin-like activity of DnaJ and the polypeptide-unfolding activity of DnaK
}

\author{
Rayees U. H. Mattoo, America Farina Henriquez Cuendet, Sujatha Subanna, Andrija Finka, \\ Smriti Priya, Sandeep K. Sharma and Pierre Goloubinoff*
}

DBMV, Faculty of Biology and Medicine, University of Lausanne, Lausanne, Switzerland

Edited by:

Rui Joaquim Sousa, University of

Texas Health Science Center, USA

Reviewed by:

Kürsad Turgay, Leibniz Universität

Hannover, Germany

Kevin Anthony Morano, UTHealth

Houston, USA

\section{*Correspondence:}

Pierre Goloubinoff, DBMV, Faculty of

Biology and Medicine, University of

Lausanne, Biophore Building,

1015-Lausanne, Switzerland

e-mail: pierre.goloubinoff@unil.ch
The role of bacterial Hsp40, DnaJ, is to co-chaperone the binding of misfolded or alternatively folded proteins to bacterial Hsp70, DnaK, which is an ATP-fuelled unfolding chaperone. In addition to its DnaK targeting activity, DnaJ has a weak thiol-reductase activity. In between the substrate-binding domain and the J-domain anchor to DnaK, DnaJ has a unique domain with four conserved CXXC motives that bind two $\mathrm{Zn}^{2+}$ and partly contribute to polypeptide binding. Here, we deleted in DnaJ this $\mathrm{Zn}$-binding domain, which is characteristic to type I but not of type II or III J-proteins. This caused a loss of the thiol-reductase activity and strongly reduced the ability of DnaJ to mediate the ATP- and DnaK-dependent unfolding/refolding of mildly oxidized misfolded polypeptides, an inhibition that was alleviated in the presence of thioredoxin or DTT. We suggest that in addition to their general ability to target misfolded polypeptide substrates to the Hsp70/Hsp110 chaperone machinery, Type I J-proteins carry an ancillary protein dithiol-isomerase function that can synergize the unfolding action of the chaperone, in the particular case of substrates that are further stabilized by non-native disulfide bonds. Whereas the unfoldase can remain ineffective without the transient untying of disulfide bonds by the foldase, the foldase can remain ineffective without the transient ATP-fuelled unfolding of wrong local structures by the unfoldase.

Keywords: Hsp70, chaperones, misfolding, unfolding, aggregation, thioredoxins, protein disulfide isomerase, cochaperones

\section{INTRODUCTION}

Anfinsen demonstrated that under optimal artificial conditions, the primary amino acid sequence of a polypeptide contains sufficient information to direct its spontaneous acquisition of a native functional three dimensional structure (Anfinsen, 1973). However, protein crowding, which in the cytoplasm of human cells may reach up to $200 \mathrm{mg} / \mathrm{ml}$ (Geiger et al., 2012; Finka and Goloubinoff, 2013), can interfere with the productive folding of de novo synthesized polypeptides to their native state. This may occur under mild oxidative stress, in particular with large multidomain polypeptides that are aggregation-prone, where wrongly aligned disulfide bonds may detrimentally stabilize misfolded conformations (Martin and Hartl, 1997; Ellis, 2001; Cabrita et al., 2010). When a labile protein is exposed to a mild stress, such as heat-shock, it may transiently expose hydrophobic segments to the aqueous environment and seek thermodynamic stability by forming non-native intra- and intermolecular beta-sheets, leading to the stabilization of insoluble protein aggregates (Dobson, 2003; Natalello et al., 2013). The non-native hydrophobic interactions of misfolded proteins with membranes and other labile members of the proteome can have toxic effects, in particular for neurons. Membrane damage can induce the formation of reactive oxygen species (ROS) and trigger chronic neuro-inflammation and apoptosis, leading to tissueloss and degenerative diseases, such as Alzheimer's, Parkinson's and aging in general (Bucciantini et al., 2002; Selkoe, 2004; Hinault et al., 2006). ROS particularly target unsaturated lipids and proteins with exposed reduced cysteines, leading to protein dysfunction, crosslinking and aggregation (Thomas and Mallis, 2001).

Prokaryotes and eukaryotes have evolved a complex network of molecular chaperones that in unstressed cells regulate the activity of alternatively- vs. natively-folded proteins such as clathrin cages vs. triskelions, and in stressed or diseases cells prevent and even actively avert the formation of cytotoxic misfolded protein conformers (Finka et al., 2011; De Los Rios and Goloubinoff, 2012). Hence, stable, potentially toxic, misfolded and aggregated polypeptide species can be actively converted by disaggregating and unfolding chaperones into harmless, natively refolded functional proteins (Parsell et al., 1994; Sharma et al., 2010; Hinault et al., 2011; Shorter, 2011; Rampelt et al., 2012; Mattoo et al., 2013). The mechanism of unfolding involves the initial binding to a chaperone surface of an otherwise stably misfolded polypeptide substrate with exposed hydrophobic surfaces. Following the ATP-fuelled unfolding and release, the unfolded intermediate may then spontaneously refold into its most stable 
native state and thus escape aggregation or chaperone re-binding (Sharma et al., 2010; Priya et al., 2013b). Similarly, the mechanism of folding by a protein disulfide isomerase involves the oxidoreduction-dependant transient covalent binding of a thioldisulfide oxidoreductase to a misaligned cysteine pair that may wrongly stabilize a tensed misfolded structures in the polypeptide. The transient opening of the misaligned cysteines may allow a relaxation of the local tensions in the misfolded polypeptide structure, thereby permitting the proper repositioning of the cysteines in the native structure (Ou et al., 2001; Irvine et al., 2014).

Prokaryotic DnaK and its eukaryotic orthologous Hsp70 and Hsp110, are polypeptide unfolding molecular machines that can use the energy of ATP hydrolysis to unfold various polypeptides in different stable conformations (Sharma et al., 2010; Mattoo et al., 2013). DnaK uses DnaJ as a substrate-recognition cochaperone that preferentially binds to misfolded (Hinault et al., 2010), or alternatively folded polypeptides (McCarty et al., 1996) with exposed hydrophobic residues, but avoid binding to compact natively-folded proteins with few exposed hydrophobic residues (Hinault et al., 2010). Thus, by way of its conserved J-domain that anchors to the nucleotide binding domain of DnaK in the ATP-bound, but not to the ADP-bound state, DnaJ may recruit a stably misfolded polypeptide to the unfolding machinery of DnaK, to be then released and refold to the native state (Sharma et al., 2010).

Escherichia coli DnaJ is a type I J-domain protein (J-protein) that, like human DNAJA1, has a conserved antiparallel beta-sheet domain with four characteristic CXXC motives, each being typical signatures of the thioredoxin catalytic site. Two $\mathrm{Zn}^{2+}$ ions can bind with high affinity to the two cysteines tetrads (Banecki et al., 1996). This compact cysteine-rich domain is flanked on one side by the conserved $8 \mathrm{kDa} \alpha$-helical J-domain, responsible for anchoring to DnaK, and on the other the $\beta$-sheet proteinbinding domain per se. This cysteine-rich domain, which is also called the zinc-finger domain, is absent in type II J-proteins, such as E. coli CbpA and human DNAJB1 (Ramos et al., 2008; Kampinga and Craig, 2010) and also from the less conserved type III J-proteins, such as E. coli DjlA and human auxilin. In the cell and also in vitro, the bacterial CbpA can substitute for DnaJ in DnaK-mediated polypeptide unfolding/refolding assays (Ueguchi et al., 1994; Bird et al., 2006; Hinault et al., 2010).

Thioredoxins are small ubiquitous redox enzymes that reduce protein disulfide bonds by using a pair of cysteine residues present in a strictly conserved WCGPC catalytic motif. Thioredoxin-2, has two WCGPC catalytic motives that can form a zinc-finger, similar to the Zinc ( $\mathrm{Zn})$ Center I and II to be found in DnaJ, each with four cysteines coordinated to a single $\mathrm{Zn}^{2+}$ (Ye et al., 2007). Zn Center I of DnaJ was reported to be essential for substrate binding and $\mathrm{Zn}$ Center II for its interaction with DnaK (Linke et al., 2003). In addition, DnaJ has also been shown to carry a weak thiol-reductase activity and it has been suggested to act as a protein disulfide isomerase (de Crouy-Chanel et al., 1995). Yet, the complete deletion of the cysteine rich domain of DnaJ did not have dramatic effects, both in vivo and in vitro ability of DnaJ to co-chaperone DnaK's activity (Wall et al.,
1994; Banecki et al., 1996). This was confirmed in protein disaggregation and refolding assays using heat-denatured glucose6-phosphate dehydrogenase $(\mathrm{G} 6 \mathrm{PDH})$ as substrate, where in the presence of $5 \mathrm{mM}$ DTT, CbpA devoid of a Zinc-finger domain was almost an equally effective DnaK co-chaperone, as DnaJ that contained a Zinc-finger domain (Hinault et al., 2010).

Here, we re-examined the function of the cysteine-rich region of DnaJ, as a putative dithiol-oxidoreductase foldase, in the light of our recent findings that human Hsp70 and Hsp110, and also bacterial DnaK, can act as catalytic ATP-fuelled polypeptide unfoldases on various stable misfolded and aggregated protein substrates (Sharma et al., 2010; Mattoo et al., 2013). We created a truncated version of DnaJ ( $\Delta$ DnaJ) lacking both $\mathrm{Zn}$ centers (residues 144-195). In vitro assays showed that the unfoldase activity of DnaK was optimal at refolding mildly oxidized substrates to the native state, when it was synergically assisted by externally added thioredoxin, or by the intrinsic thiol-reductase activity of wild type DnaJ. Reciprocally, the thiol-reductase activity of E. coli thioredoxin was effective at refolding mildly oxidized substrates only when it was synergically assisted by the ATP-dependant unfoldase activity of DnaK.

\section{MATERIALS AND METHODS PROTEINS}

DnaK, DnaJ, and $\Delta$ DnaJ purification was according to Gur et al. (2004). GrpE was a gift from H.-J. Schönfeld, F. Hoffmann-La Roche, Basel, Switzerland. Glucose-6-phosphate Dehydrogenase (G6PDH) from Leuconostoc mesenteroides, Bovine rhodanese, Bovine Insulin and Thioredoxin from Spirulina sp. was purchased from Sigma-Aldrich. Protein concentrations were estimated by the Bradford Assay and protein concentrations were always expressed in protomer.

\section{INSULIN TURBIDITY ASSAY}

The insulin turbidity assay was performed as described in Holmgren (1979) with following modifications; Native insulin $(0.13 \mathrm{mM})$ supplemented either with thioredoxin $(1 \mu \mathrm{M}$ and $10 \mu \mathrm{M})$, DnaJ $(30 \mu \mathrm{M})$ or $\Delta \mathrm{DnaJ}(30 \mu \mathrm{M})$ in presence of $0.45 \mathrm{mM}$ DTT (Sigma-Aldrich). Light scattering of aggregates formed was measured in a fluorimeter at $650 \mathrm{~nm}$.

\section{CHAPERONE REFOLDING ASSAYS}

Heat-preaggregated G6PDH was refolded by the DnaK chaperone system as described in Ben-Zvi et al. (2004), with the following modifications; $650 \mathrm{nM}$ heat-aggregated G6PDH (final concentration) was reactivated in the presence of $5 \mu \mathrm{M} \mathrm{DnaK}$, incrementing (0-3.5 $\mu \mathrm{M}$ ) DnaJ/ $\Delta$ DnaJ, $2 \mu \mathrm{M}$ GrpE (the full DnaK chaperone system) and $5 \mathrm{mM}$ ATP. G6PDH activity was measured at different times of chaperone-mediated refolding reaction at $30^{\circ} \mathrm{C}$. Urea-denatured rhodanese was refolded by the DnaK chaperone system as described in Mendoza et al. (1991) with the following modifications; Urea inactivated rhodanese $(500 \mathrm{nM})$ was refolded at $25^{\circ} \mathrm{C}$, in the presence of limited amounts of DTT $(0.1 \mathrm{mM})$, without or with DnaK $(3 \mu \mathrm{M})$, DnaJ or $\Delta \mathrm{DnaJ}(1.6 \mu \mathrm{M})$, GrpE $(1 \mu \mathrm{M}), \operatorname{ATP}(5 \mathrm{mM})$ and with or without Thioredoxin $(1 \mu \mathrm{M})$. 


\section{RECONSTITUTION OF A TYPICAL DNAJ DIMER FROM PUBLISHED STRUCTURES OF J-PROTEINS \\ Method}

The various structures of J-proteins from Protein Data Bank (PDB) were aligned using the align function in the PyMOL program and were also sequence-aligned according to the multiple sequence alignment with hierarchical clustering (Corpet, 1988). The various missing structures in the E. coli DnaJ dimer were approximated from the overlapping structures from the closest sequence-relatives of DnaJ. The final structure in Figure 1B is composed of the J-domain from E. coli (PDB: 1BQ0), the cysteine-rich region and most of the C-terminal domain from yeast DnaJ, ydj1 (PDB:1NLT) and the dimerization interface was contributed by the human hdj1 (PDB: 3AGY), see also Supplementary Figure 1.

\section{RESULTS \\ SEQUENCE AND STRUCTURAL COMPARISONS SHOW THAT TYPE II J-PROTEINS LACK A CONSERVED CYSTEINE-RICH DOMAIN COMMON TO ALL TYPE I J-PROTEINS}

Amino acid sequence alignment of DnaJ and CbpA, which are the main J-domain co-chaperones in E. coli, show a very high homology of their respective N-terminal J-domains (Figure 1A, Green background) and a good homology of their C-terminal protein-binding domains (Figure 1A, gray). Amidst the J-domain and protein-binding domain, DnaJ has a conserved Zn-binding domain with four characteristic CXXC pairs at conserved positions of the anti-parallel beta-sheet (Figure 1A, cysteines in purple). Whereas the E. coli CbpA sequence is devoid of cysteines and plainly lacks this domain, corresponding to residues 144-195 in DnaJ, these residues encode for most of the Zn-finger

A CbPA M---ELKDYYATMGVKPTDDLKTIKTAYRRLARKYHPDVSK-EPDAEARFKEVAEAWEVLSDEQRRAEYDQMWQHRNDPQFNRQFHHGDGQSFNAEDFDDIFSSIF DnaJ M---AKODYYEILGVSKTAEEREIKKAYKRLAMKYHPDRNOGDKEAEAKFKEIKEAYEVLTDSOKRAAYDQYGHAAFEOGMGGGGFG-GGADFSDIFGDVFGDIF DNAJA1 M--VKETTYYDVLGVKPNATOFELKKAYRKI.ALKYHPDKNPNEGE---KFKOISOAYEVLSDAKKREIYDKGGEOAIKEGGAGGGFGS-PMDIFDMFFGGG-----

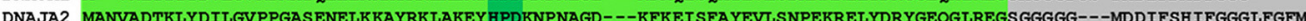
D DNAJB1 M----GKDYYQTLGLARGASDEEIKRAYRRQALRY HPDKNKEPG-AEEKFKEIAEAYDVLSDPRKREIFDRYGEEGLLGSGPSGGSGG-GAN------GTSFSYTF
DNAJB4 M----GKDYYCILGIEKGASDEDIKKAYRKQALKFHPDKNKSPQ-AEEKFKEVAEAYEVLSDPKKREIYDQFGEEGLKGGAGGT----DGQ----GGTFRYTF

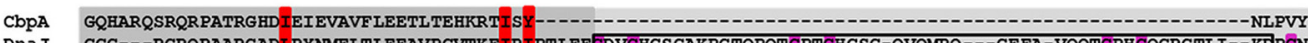

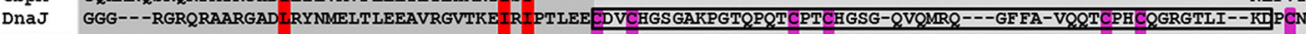
DNAJA1 GRMQ--RER----RGKNVVHQLSVTLLDLYNGATRKL ALQKNVICDKCEGRGGKKGAV-EC CPNCRGTGMQIRIHQIGPGMVQ I ISVCME CQGHGERISPKDRCK DNAJA2 GNQS--RSRNGRRRGEDMMI PLKVSLEDLYNGKTTKLQL SKNVLCSACSGQGGKSGAV-QKCSACRGRGVRIMIRQIAPGMVQQMQSVCSD CNGEGEVINEKDRCK DNAJB1 HGDP--HAMFAEFFGGR PFDTFFGQRNGEEGMDIDDPFSGFPM-----GMGGFTNVNFGRSRSAQEPARKKQDPPVTHDLRVSLEEIYSGCTKKMKI----SHKRI DNAJB 4 HGDP--HATF AAFFGGSNPFEIFFGRRMGGGRDSEEMEIDGDPF------SAFGF SMNGYPRDRNSVGPSRLKQDPPVIHELRVSLEEIYSGCTKRMKI----SRKRL

CbPA NAFGMIEQEI PKTLNVKIPAGVGNGQRIRLKGQGTPGENGGPNGDLWLVIH IAPHPLFDIVGQDLEIVVPVSPWEAALGAKVIVPTLKES--ILLTIPPGS-QAGQ DnAJ KCHGHGRVERST SVKIPAGVTGDRIRLAQEGEAGEHGAPAGDLYVOVOVKOHPIFERE GNNLYCEVPINFAMAALGGE IEVPTLDGR--VKLKVPGET- $Q T$ TGK $\begin{array}{ll}\text { DnaJ } & \text { KCHGHGRVERSKT SVKIPAGVDTGDRIRLAGEGEAGEHGAPAGDL YVQVQVKQHPIFERE GNNLYCEVPINFAMAALGGE IEVPTLDGR--VKLKVPGET-QTGK } \\ \text { DNAJA1 } & \text { SCNGRKIVREKKILEVHIDKGMKDGQKITF HGEGDQ-EPGLPGDIIIVLD QKDHAVFTRR GEDLFMCMDIQLVEALCGFQKPI STLDNRT IVITSHPGLIVKHGD }\end{array}$ DNAJA1 SCNGRKIVREKKI EVHIDKGMKDGQKITF HGEGD Q-EPGLEPGDIIIVLDQKDHAVFTRRGEDLFMCMDI QLVEALCGFQKPI STLDNRT IVITSHPG $Q$ IVKBGD
DNAJA2 KCEGKKVIKEVKI EVHVDKGMKHGQRITFTGEADQ-APGVEPGDIVLLLQEKEHEVFQRD GNDLHMTYKIGLVEALCGFQFTFKHLDGRQIVVKY PPGKVIEPGC DNAJA2 KCEGKKVIKEVKI EVHVDKGMKHGQRITF TGEADQ-APGVEPGDIVLLLQEKEHEVFQRD GNDLHMTYKI GLVEALCGFQFTFKHLDGR IVVKYPPGKVIEPGC
DNAJB1 NPDGKSIRNEDKI TIEVKKGWKEGTKITF PKEGDQ-TSNNIPADIV VVLKDKPHNIFKRD GSDVIYPARI SLREALCGCTVNVPTLDGRTIPVVF--KDVIRPGM DNAJB4 NADGRSYRSEDKILTIEIKKGWKEGTKITF PREGDE-TPNS IPADIVEIIKDKDHPKFKRDGSNII YTAKI SLREALCGCS INVPTLDGRNIPMSV--NDIVKPGM

CbPA RLRVKGKGLVSKKQT---GDLYAVLKIVMP PK-PDENTAALWQQLADAQSSF---DPRKDWGA-DNAJ LFRMRGKGVKSVRGGAQ-GDLLCRVVVETPVG--LNEKQKQLLQELQESFGGP--TGEHNS PRSKSFFDGVKKFFDDLTR-DNAJA1 IKCVLNEGMPIYRRPYEKGRLIIEFKVNFP ENGFLSPDKLSLLEKLLPERKEVEET-DEMDOVELVDFDPNO-----ERRR HYNGEAYEDDEHHPRGGVQCQTS DNAJA2 VRVVRGEGMPQYRNPFEKGDLYIKFDVOFPENNWINPDKLSELEDLLPSRPEVPNIIGETEEVELQEFDSTRGSGGGRREAYNDSSDEESSSHHGPGVQCAHQ DNAJB1 RRKVPGEGLPLPKTPEKRGDLIIEFEVIFPER--I PQTSRTVLEQVLPIDNAJB1 RRKVPGEGLPLPKTPEKRGDLIIEFEVIFPER-IPQTSRTVLEQVLPI-ISA

B

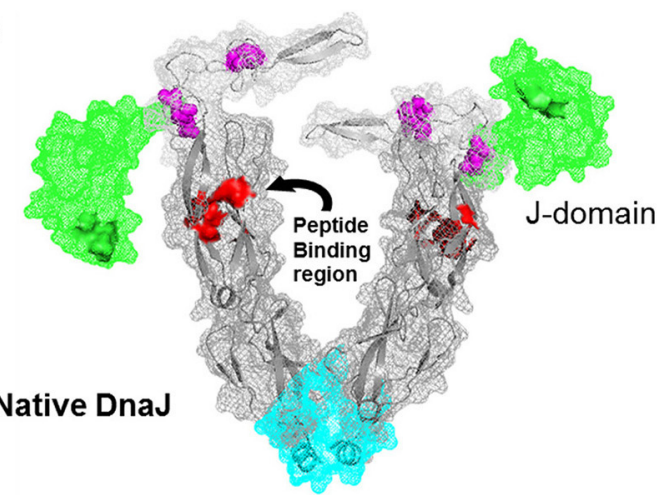

FIGURE 1 | Sequence alignment of the two most abundant human and bacterial J-proteins. (A) Amino-acid sequence alignment of the two most abundant Hsp40-like J-proteins in Escherichia coli bacteria CbpA and DnaJ, and the four most abundant Hsp40s in human: the type I J-proteins DNAJA1 and DNAJA2 and type II J-proteins DNAJB1 and DNAJB4. The conserved $\mathrm{N}$-terminal J-domain (light green) with the conserved HPD motif (deep green) is followed by a G/F rich hinge region. In DnaJ, DNAJA1 and DNAA2, this is followed by a Zinc binding domain (light gray) with four pairs of highly conserved cysteines (purple), which are absent in CbpA, or different in DNAJB1 and DNAJB4. This is followed by a C-terminal peptide-binding domain (PBD) (dark gray) with the residues involved in peptide binding groove

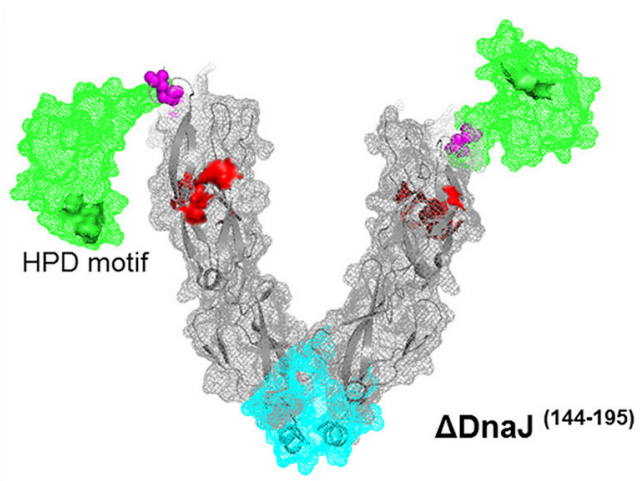

shown in red and the putative dimerization interface shown in cyan. The black rectangular frame shows the 51 cysteine-rich residues, which we deleted from bacterial DnaJ that optimally match domain alignments with CbpA. (B) Left panel: Approximate 3D structure of a typical DnaJ dimer, reconstructed from sequence and structural alignments of various partial $X$-ray crystallographic structures from bacteria, yeast and human Hsp40s (PDB: $1 \mathrm{XBL}$ the $E$. coli J-domain; $1 \mathrm{EXK}$ for the $E$. coli cysteine rich domain; $1 \mathrm{NLT}$ for the yeast YDJ1 PBD+cysteine rich domain; 3AGZ for the human HDJ1 for half PDB+dimerization+two bound peptides; 2QLD for the human HDJ1 for Half PDB+dimerization). Right panel: The structure of mutant DnaJ ( $\Delta$ DnaJ). The colored segments are as in (A). 
motives. Confirming this, the crystal structure of the Thermus thermophilus DnaJ ${ }_{2}$ dimer, which is typical CbpA ortholog, lacks cysteines and has no Zn-finger domain (Barends et al., 2013). Sequence alignments of E. coli DnaJ and CbpA with four of the most abundant J-domain proteins in the human cytoplasm (Finka and Goloubinoff, 2013), confirmed that human DNAJA1 and DNAJA2 contained the four characteristic CXXC pairs at conserved positions as in DnaJ, whereas DNAJB1 and DNAJB4 contained a slightly shorter middle domain lacking cysteines (Kampinga et al., 2009; Kampinga and Craig, 2010) (Figure 1A).

In an attempt to understand the particular function of the $\mathrm{Zn}$ fingers in type I J-domain proteins, we produced an E. coli DnaJ mutant lacking residues 144-195. Alignments showed that the deletion precisely corresponded to the missing cysteine-rich segment in CbpA (Figure 1A). Noticeably, among the four conserved pairs, the most distal C-terminal CXXC pair has been shown to contribute to the binding of substrate polypeptides to DnaJ (Linke et al., 2003). As sequence alignments in various CbpAs and DnaJs suggested that this segment should be present but lack cysteines, our CbpA-mimetic $\triangle \mathrm{DnaJ}$ was designed to still contain the most C-terminal cysteine pair out of the four pairs present in wild-type (WT) DnaJ.

We used partially resolved X-ray crystal structures from various orthologs of J- proteins from eukaryotic and prokaryotic type I and Type II J-proteins (see Materials and Methods), to generate a $3 \mathrm{D}$ reconstruction model of a typical E. coli DnaJ dimer (for $3 \mathrm{D}$ view of the DnaJ dimer, watch Movie 3DHsp40) (Figure 1B). Confirming the validity of our reconstruction, the model showed a very high structural homology with the near complete X-ray structure of the type II dimer of Thermus thermophilus DnaJ $)_{2}$, which is devoid of cysteines (Supplementary Figures 1A,B). In the model, the cysteine-rich domain (Figure 1B, purple cysteine pairs) appeared as an independent, compactly folded middle domain, without apparent close interactions with the flanking domains: It was merely connected at E143 to the N-terminal J-domain (Figure 1B, green), and at P196 to the C-terminal protein-binding domain (Figure 1B, gray background, peptidebinding residues in red). Because in the DnaJ structure positions for E143 and P196 are in close vicinity, the deletion of the 51 interspacing residues in $\Delta \mathrm{DnaJ}$ was not expected to cause any significant structural tension or destabilization in the other parts of the molecule (Figure 1B right). Thus, the $\Delta \mathrm{DnaJ}$ mutant was a structural mimetic of CbpA. We next used well-established stringent in vitro ATP-DnaK-dependant, GrpE-regulated protein unfolding/refolding refolding assays, to address the specific role of the cysteine-rich domain in Type I, as compared to Type II J-proteins cochaperones.

\section{WILD-TYPE DNAJ BUT NOT $\triangle$ DNAJ CAN CATALYZE THE REDUCTION OF INSULIN}

When supplemented with $10 \mathrm{mM}$ DTT, mature insulin readily forms large turbid aggregates that within minutes maximally scatter light at $650 \mathrm{~nm}$ (Holmgren, 1979). In contrast, in the presence of limiting DTT $(0.45 \mathrm{mM})$, the very low light-scattering signal of native insulin did not increase during the first $60 \mathrm{~min}$ of the assay, indicating that within this time range, the low concentration of
DTT was poorly effective at reducing insulin into aggregationprone species that scatter light (Figure 2A). Expectedly, when in the presence of $0.45 \mathrm{mM}$ DTT, $1 \mu \mathrm{M}$ or $10 \mu \mathrm{M}$ of E. coli thioredoxin were added, insulin turbidity rapidly increased at the respective rates of $1 \% \mathrm{~min}^{-1}$ and $10 \% \mathrm{~min}^{-1}$ (maximal velocities were measured at the inflection point of the sigmoidal curves) (Figure 2B). When instead of thioredoxin, WT DnaJ $(30 \mu \mathrm{M})$ was added, insulin turbidity also steadily increased, yet at a slow rate of $0.4 \% \mathrm{~min}^{-1}$ (Figures $2 \mathrm{~A}, \mathbf{B}$ ). In contrast, the same amount of $\triangle \mathrm{DnaJ}$ remained ineffective at accelerating insulin reduction, demonstrating that the $\mathrm{Zn}$-fingers domain of DnaJ carries a mild thiol-reductase activity.

\section{$\Delta$ DnaJ functions as a bona fide DnaK targetase}

We next addressed the ability of $\Delta \mathrm{DnaJ}$, as compared to WT DnaJ, to target a stable pre-aggregated substrate onto the DnaK unfolding chaperone machinery. We used as model substrate, the cysteine-less G6PDH enzyme, which was first heat-preaggregated

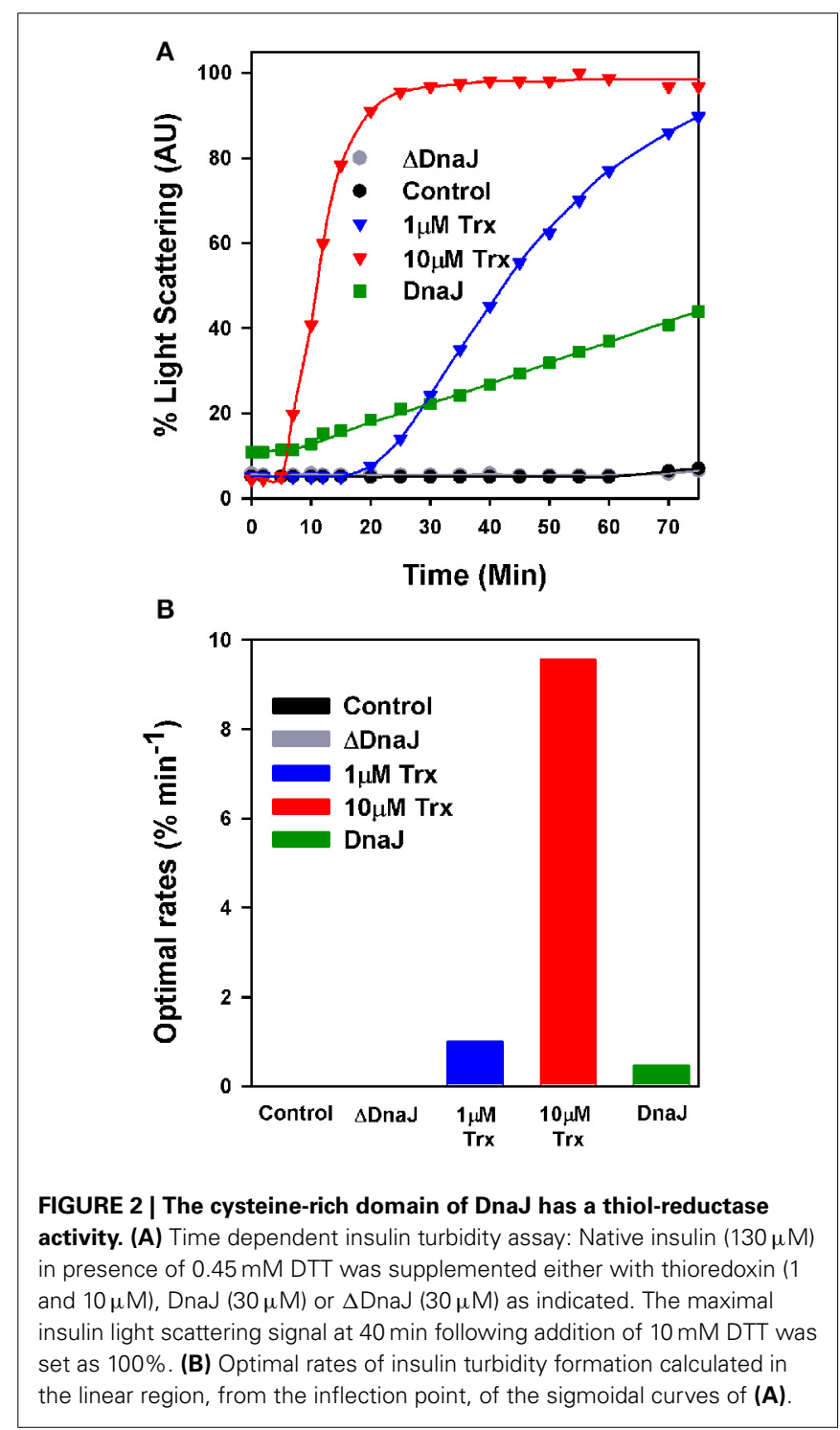


in the absence of chaperone (Diamant et al., 2000; Hinault et al., 2010) and subsequently supplemented with constant concentrations of DnaK, GrpE and ATP, and increasing concentrations of $\Delta$ DnaJ or DnaJ, as indicated (Figure 3). The time-dependent reactivation of G6PDH by DnaK, GrpE and ATP at $30^{\circ} \mathrm{C}$ in the presence of increasing amounts of $\triangle \mathrm{DnaJ}$ or WT DnaJ (Figure 3A) provided maximal refolding rates, which were plotted against the J-co-chaperone concentrations (Figure 3B). The chaperone reactions were found to be driven equally well by 1.6 $\mu \mathrm{M}$ WT DnaJ as by $3.2 \mu \mathrm{M} \Delta \mathrm{DnaJ}$, at an apparent maximal refolding rate of $30 \mathrm{nM} \mathrm{min}-1$. This demonstrates that under the fully reducing conditions (10 $\mathrm{mM}$ DTT) of the in vitro assay, the Zn-finger domain was not essential for the ATP-fuelled unfolding/refolding of stable pre-aggregated polypeptides by DnaK. This was not unexpected, as CbpA that naturally lacks a Zn-finger domain, has been shown earlier to carry a bona fide DnaJ-like (Mattoo and Goloubinoff, 2014) co-chaperoning activity in vitro (Gur et al., 2004; Hinault et al., 2010; Mattoo and Goloubinoff, 2014). Noticeably, 2.5 times more $\Delta \mathrm{DnaJ}(1 \mu \mathrm{M})$ was needed to achieve half the maximal refolding rates of the reaction than WT DnaJ $(0.4 \mu \mathrm{M})$. Thus, $\Delta \mathrm{DnaJ}$ had an apparent lower affinity for the misfolded G6PDH substrate than WT DnaJ, similar to CbpA (Hinault et al., 2010) and in agreement with the earlier observations by Linke et al. (2003) that the Zn-binding domain participates, although is not essential to substrate binding.

When the reaction was performed without DTT, the ATPfuelled DnaK-DnaJ-GrpE-mediated refolding of stably heatdenatured G6PDH was strongly reduced. Although this reduction can be attributed in part also to a possible oxidation of the single cysteine residue at position 15 of DnaK, the decrease of the chaperone performance was noticeably more pronounced with the cysteine-rich DnaJ than for the cysteine-deficient $\Delta$ DnaJ. Thus, without DTT, the activity of $1.6 \mu \mathrm{M}$ DnaJ was 6 fold slower than with DTT, as compared to only 3 fold slower in the case of $1.6 \mu \mathrm{M}$ $\Delta \mathrm{DnaJ}$ (Figure 3B). This suggests that under non-reducing conditions, the highly reactive cysteines in type $1 \mathrm{~J}$-co-chaperones may form various covalent bonds with other exposed cysteines in DnaJ and possibly with the single cystein of DnaK (but not with the substrate which is cysteine-less) that adversely affect substrate processing by DnaK.

\section{THIOREDOXIN POTENTIATES THE DNAK UNFOLDASE ACTIVITY AND DNAK POTENTIATES THE THIOREDOXIN FOLDASE ACTIVITY}

We next used urea- pre-denatured rhodanese, which at varience with G6PDH, contains four cysteines and is accordingly an oxidation-sensitive stringent protein substrate of DnaK (Natalello et al., 2013), to address the possible contribution of the thioldisulfide oxidoreductase activity of DnaJ's Zn-finger domain to the ATP-fuelled unfolding/refolding activity of DnaK. Urea-preunfolded rhodanese was diluted in $0.1 \mathrm{mM}$ DTT, without or with $1 \mu \mathrm{M}$ of E. coli thioredoxin, ATP, DnaK, GrpE and DnaJ (KJE) or $\triangle \mathrm{DnaJ}(\mathrm{K} \Delta \mathrm{JE})$, as specified. With ATP, DnaK together with GrpE and DnaJ expectedly drove the native refolding of ureadenatured rhodanese at the maximal rate of $23.6 \mathrm{nM} \mathrm{min}^{-1}$. As in the case of DnaK-mediated refolding of heat-predenatured G6PDH, the rate was about twice faster with DnaJ than with $\triangle \mathrm{DnaJ}$ (Figure 4A). Noticeably, thioredoxin ( $\operatorname{Trx} 1)$ alone or with

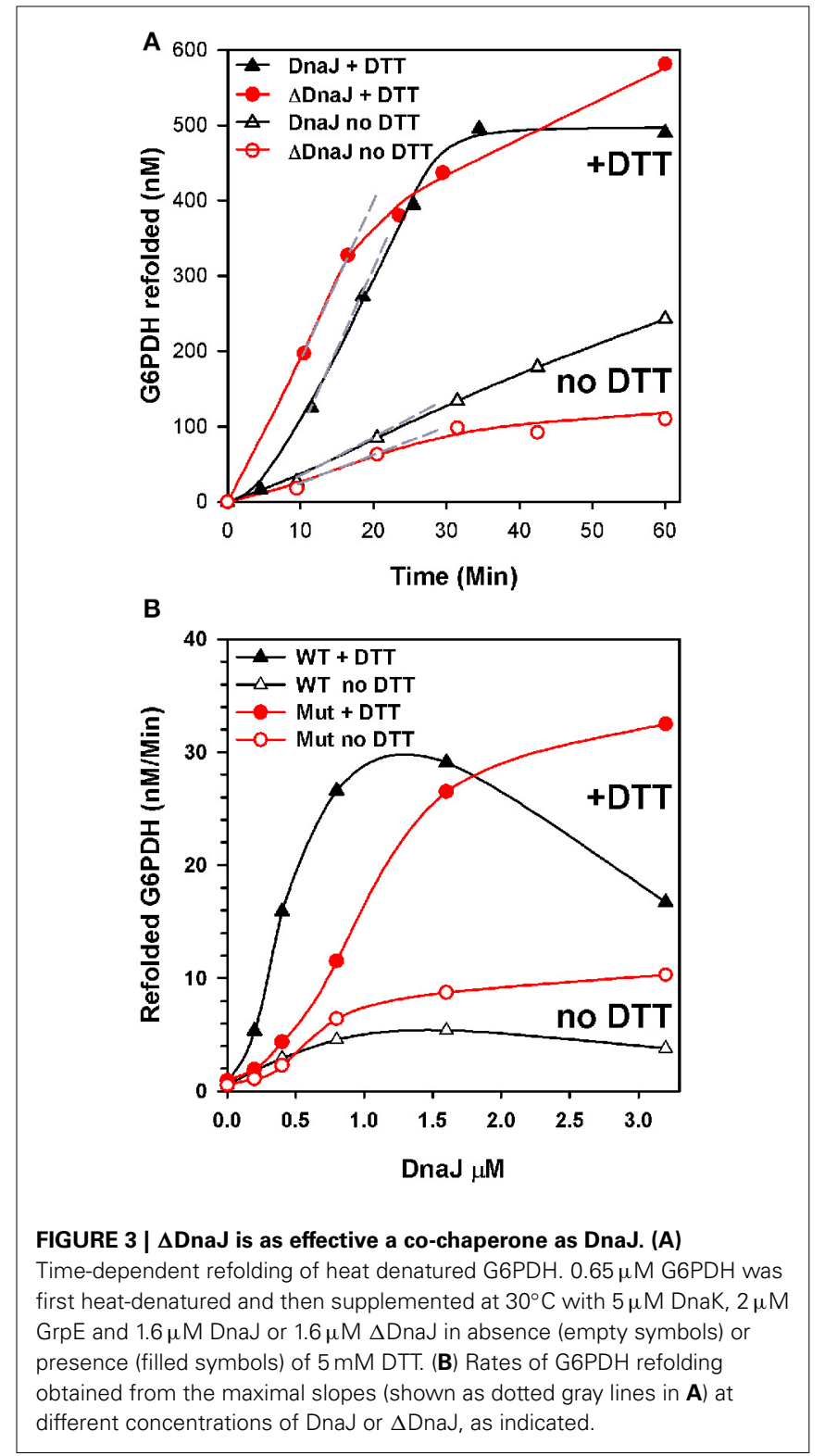

KJE chaperones but without ATP, did not drive any significant spontaneous rhodanese refolding (Figure 4B). In contrast, with ATP, thioredoxin doubled the rates of the chaperone reaction. In the first $15 \mathrm{~min}$ of the reaction, the thioredoxin effect was more pronounced in the case of the $\Delta$ DnaJ- than of the DnaJmediated reaction (Figure 4C), suggesting that thioredoxin could complement the slow, yet significant effect of the cysteine-rich domain of the wild type DnaJ, which was completely lacking in $\Delta$ DnaJ. Thus, the unfolding action of the DnaK chaperone synergistically activated, remarkably in an ATP-dependent manner, the "foldase" activity of thioredoxin. Reciprocally, thioredoxin synergistically activated the ATP-driven unfolding/refolding activity of the DnaK chaperone, as the thioredoxin contribution was more effective with $\Delta \mathrm{DnaJ}$ that lacked thioredoxin-like foldase activity, than with DnaJ that already carried an intrinsic thioredoxin-like activity of its own (Figures 4C,D). 

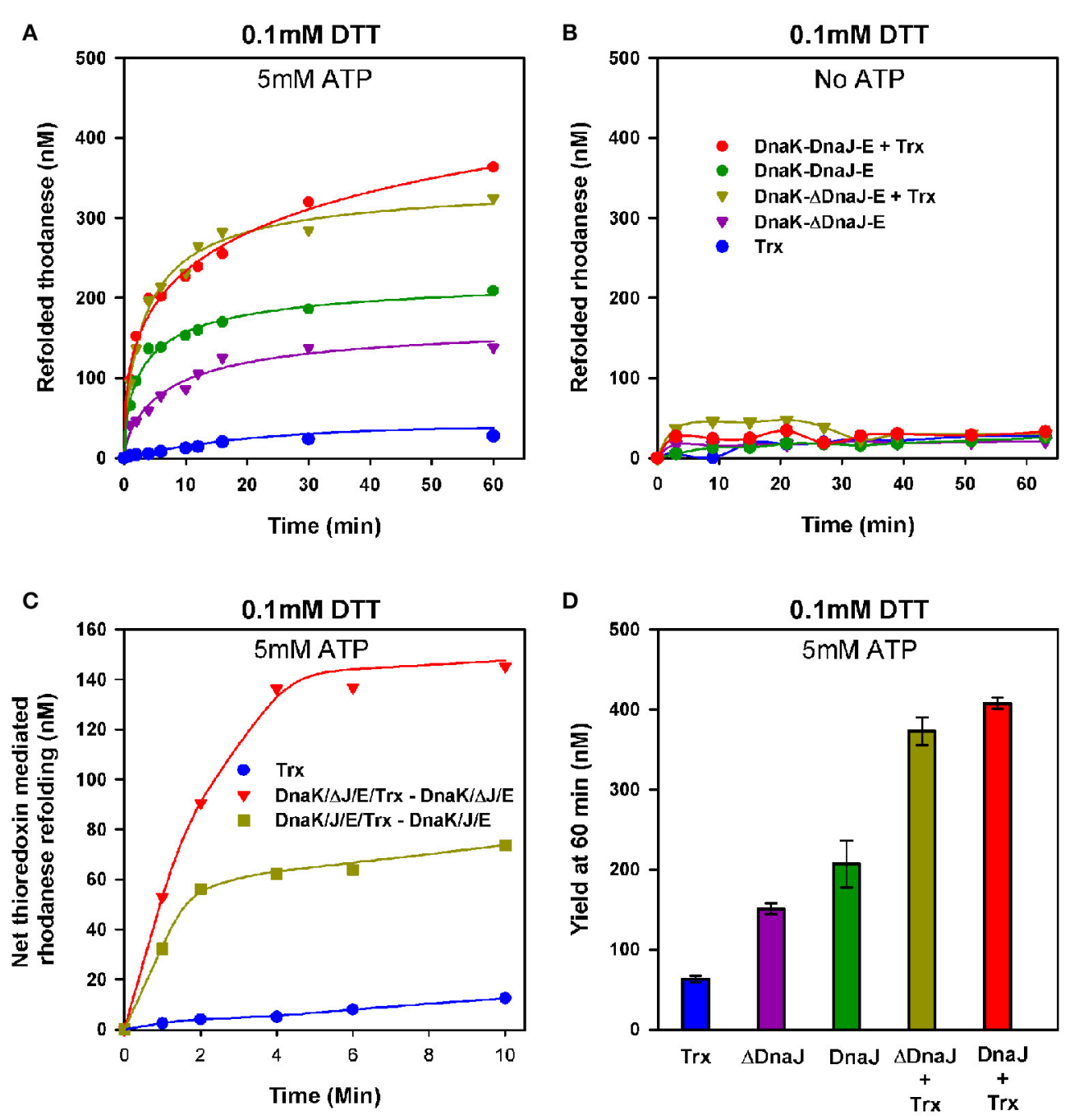

FIGURE 4 | Thioredoxin-1 enhances unfolding of oxidized polypeptide substrates by DnaK. (A) Urea inactivated rhodanese $(0.5 \mu \mathrm{M})$ was refolded at $25^{\circ} \mathrm{C}$, under limited amounts of DTT $(0.1 \mathrm{mM})$, without or with $3 \mu \mathrm{M}$ DnaK, $1.6 \mu \mathrm{M}$ DnaJ or $\Delta$ DnaJ, $1 \mu \mathrm{M}$ GrpE and $5 \mathrm{mM}$ ATP in absence or presence of $1 \mu \mathrm{M}$ Thioredoxin

as indicated. (B) Refolding of urea inactivated rhodanese under the same conditions as in (A), but without ATP. (C) The net effect of added thioredoxin upon DnaJ or $\triangle$ DnaJ in DnaK-DnaJ-GrpE mediated refolding, from (A). D) Yield of rhodanese refolded at $60^{\prime}$ under similar conditions as in (A).

\section{DISCUSSION}

By virtue of their conserved J-domain that specifically "locks" into the ATP-bound Hsp70 unfolding chaperone machines, J-proteins can specifically target various polypeptide substrates that need, at some point, to be unfolded in the cell (Mattoo and Goloubinoff, 2014). The binding of a J-domain to Hsp70 also triggers ATP hydrolysis, which in turn causes the tight closure of the lid onto the base of the protein-binding domain. This closure can apparently apply a local "clamping" destabilizing force onto an entrapped bulky secondary structure from the bound polypeptide substrate and entropically pull on it (De Los Rios et al., 2006; Baneyx and Nannenga, 2010; Sharma et al., 2010). Following ADP-accelerated release from Hsp70/Hsp110 by a nucleotide exchange factor (bacterial GrpE, or eukaryotic Bags), the locally unfolded polypeptides may then dissociate and spontaneously reach the stable native state with a low affinity for J-proteins and for the Hsp70/Hsp110 chaperones (Sharma et al., 2010; Priya et al., 2013a; Mattoo and Goloubinoff, 2014). Thus, auxilin is a J-protein that can target Hsc70 onto clathrin cages, to be locally pulled upon and deoligomerized into triskelions (Ma et al., 2002; Jiang et al., 2003). Zuotin is a J-protein that can target HSPA14 onto de novo synthesized polypeptides exiting the ribosome, to be pulled upon, unfolded and imported into the cytoplasm (Gautschi et al., 2001), Sec63 can target BIP onto partially folded cytoplasmic polypeptides, to be pulled upon, unfolded and imported into the ER lumen (Misselwitz et al., 1999) and PAM18:PAM16 targets mHsp70 onto partially folded cytoplasmic polypeptides to be pulled upon, unfolded and imported into the mitochondrial matrix (Pais et al., 2011). Similarly, following stress, human DNAJA1 or bacterial DnaJ and CbpA can target 
stable stress-misfolded and aggregated inactive proteins, respectively onto human Hsc70 and Hsp110, or bacterial DnaK, to be pulled upon, unfolded into natively refoldable proteins (De Los Rios et al., 2006; Mattoo et al., 2013; Priya et al., 2013a). Suggesting a catalytic action of the J-domain cochaperones, their copy number in the various compartments of the human cell is about one order of magnitude lower than the sum of their target chaperone partners (the cytoplasmic Hsp70, Hsc70 and Hsp110s, the ER BIP and Grp170 and mitochondrial mtHsp70) (Finka and Goloubinoff, 2013). Likewise, in log growth phase, the copy number of the E. coli J-proteins is about 6 times less than DnaK and HscA (Arike et al., 2012). Moreover, in vitro chaperone refolding assays showed that 20 times less DnaJ molecules compared to DnaK sufficed to drive the ATP-dependent stringent refolding of stable heat-denatured proteins at half maximal rate (Hinault et al., 2010). Together, this suggests that in each E. coli cell, 6000 molecules of DnaK unfoldases can be optimally put in relation with misfolded polypeptide substrates by merely 180 DnaJ dimers implying multiple iterative cycles of co-chaperone binding and release (Hinault et al., 2011; Arike et al., 2012).

On top of the well-established DnaK polypeptide targetingfor-unfolding function of DnaJ, we addressed here a particular thiol-disulfide oxidoreductase sub-function, which we found to be specifically associated to the cysteine-rich domain of DnaJ, as a characteristic of type I J-proteins in general. Under reducing conditions as in the unstressed cytoplasm, the thiol-disulfide oxidoreductase activity was expectedly nonessential. DnaJ and $\Delta$ DnaJ mutant that was deleted in the 55 residue cysteine-rich domain, both drove at the same maximal velocity the ATPfuelled DnaK-driven unfolding/refolding of stable pre-aggregated polypeptide substrates. This confirmed earlier observations that under reducing conditions, natural type II and III J-proteins, such as CbpA, DjlA or human DNAJB1 and DNAJB4 can functionally replace type I J-proteins (Ueguchi et al., 1994; Bird et al., 2006; Hinault et al., 2010). Mutations in DnaJ have shown that although non-essential, the $\mathrm{Zn}$-binding domain contributes in part to the binding of the protein substrate (Linke et al., 2003). Indeed, we found that the $\mathrm{EC}_{50}$ value for $\Delta \mathrm{DnaJ}$ was about three times higher than for DnaJ, suggesting that type II J-proteins in general may bind less tightly to their misfolded substrates (Figure 3B).

Under mildly oxidative conditions, we found that the cysteinerich domain was central to the ability of the Hsp70 chaperone to act on partially oxidized misfolded substrates as an ATPdependant unfolding machine and to successfully convert them into natively refolded proteins. The effective thiol-reductase activity of WT DnaJ on insulin under limited reducing conditions, which we found to be missing in the $\Delta$ DnaJ, was a strong evidence that in order to accelerate the transfer proton and electrons from DTT to the oxidized disulfide bonds of the misfolded rhodanese substrate, DnaJ must have been able to transiently form covalent bonds between its cysteine-rich domain and the target misfolded polypeptides.

In addition to thioredoxin-1, which has a unique WCGPC motif, E. coli also expresses under stress thioredoxin-2 that carries two additional CXXC pairs and binds zinc with a very high affinity. Thioredoxin-2 is as efficient as thioredoxin- 1 at reducing disulfide bonds in proteins (Collet et al., 2003). This indicates that the tight Zinc binding by the CXXC motives of type $1 \mathrm{~J}$ proteins is not incompatible with their apparent ability to carry a catalytic thiol-disulfide oxidoreductase activity. Possibly, the role of the two $\mathrm{Zn}$ ions is to merely stabilize the anti-parallel beta-sheet conformation of the cysteine-rich domain.

The presence of both type I and II J-proteins in the eukaryotic cytosol suggests that without stress, both type I and II may be nearly as effective co-chaperones of the Hsp70s and Hsp110s. Yet, under mild oxidative stress, type I J-proteins may provide a powerful synergism between their intrinsic thiol-disulfide oxidoreductase "foldase" type of activity and the ATP-fuelled polypeptide unfoldase activity of Hsp70s and Hsp110s.

How may a thiol-disulfide oxidoreductase act as a polypeptide foldase? When binding to a tensed misaligned disulfide bond in a misfolded polypeptide, the enzyme is expected to transiently open it. This may suffice to release structural tensions in the polypeptide which can then reach a more native conformation, which upon the thiol-disulfide oxidoreductase dissociation can either form a new stabilizing disulfide bond between properly aligned cysteine pairs, or necessitate the assisted reduction of the cysteines by NADPH-dependant or glutathione thioredoxin reductates (Creighton and Goldenberg, 1984; Schwaller et al., 2003). Our results showed that the cysteine rich domain conferred an intrinsic thiol-disulfide oxidoreductase "foldase" activity to DnaJ, which is lacking in $\Delta \mathrm{DnaJ}$ and could be partially alleviated upon external addition of thioredoxin.

Thioredoxin-like proteins are essential to the folding of mildly oxidized proteins in cellular compartments that are often exposed to oxidative stress, such as the ER lumen or the chloroplast that accumulate ROS during photosynthesis. The Bundle Sheath Defective-2 (BSD2) is a 129-residue chloroplast imported protein, which is important for the proper assembly of the RubisCO holoenzyme (Brutnell et al., 1999). In chloroplast of angiosperms and gymnosperms (Supplementary Figure 2, upper panel), mature BSD2 is likely a 86 residues protein with four typical CXXC pairs that can form two Zn-fingers, as in the case of the cysteine rich domain of Type I J-proteins (Supplementary Figure 2, lower panel). Because it lacks a typical J-domain to bind Hsp70s, it is wrongly annotated as a member of the DnaJ/Hsp40 superfamily. Yet, its strong homology with the cysteine-rich domain of type I J-proteins suggests that when expressed in these cellular compartments, type II J-proteins that are less effective at chaperoning the Hsp70-mediated unfolding of partially oxidized misfolded proteins, might be synergized in trans by thiol-disulfide oxidoreductase, such as BSD2.

With some exceptions, proteins in the reducing environment of unstressed eukaryotic cytosol or bacterial cytoplasm have no disulfide bonds and they rarely align vicinal cysteines that could form a disulfide bond under oxidative stress without damaging the native structure (Kolberg et al., 2004; Saaranen and Ruddock, 2013). For example, in the bovine rhodanese structure, the two closest cysteine residues $\left(\mathrm{C}_{248}, \mathrm{C}_{255}\right)$ don't face each other and are $7.5 \AA$ apart, implying that the formation of $2.05 \AA$-long disulfide bonds under mild oxidative stress, would have to stabilize only severely distorted non-native conformation of the polypeptide. Under such conditions, the intrinsic thiol-disulfide oxidoreductase activity associated to the Type I J-proteins of 
the Hsp70 systems (DnaK-DnaJ-GrpE) in the cytosol, which by virtue of their ability to specifically bind to misfolded proteins rather than to natively folded or natively unfolded proteins (Hinault et al., 2010) would provide a great advantage to the cell's attempts to rescue misfolded mildly oxidized polypeptides, such as rhodanese, stabilized by wrong disulfide bonds.

Working with mildly oxidized misfolded rhodanese, which contains four cysteines, we observed that the DnaJ mutant lacking a thiol-oxidoreductase activity of its own, was less effective at mediating the DnaK-ATP-mediated unfolding/refolding reaction than wild type DnaJ that contain a thiol-oxidoreductase activity of its own (Figure 4A). This stongly suggests that a major limiting factor of the ATP-mediated unfolding/refolding reaction was the presence of wrong disulfide bonds in the substrate, rather than in the DnaK and DnaJ molecules, which needed to be transiently opened by the cysteine rich domain or by externally added thioredoxin, in order to be effectively unfolded and refolded to the native state.

Together, our data suggest that in case the mere transient opening of a wrong disulfide bond by the inbuilt thiol-disulfide oxidoreductase domain of the Type I J-protein, does not suffice to disentangle a polypeptide from its severely distorted conformation (Figure 5, lower path), the bound co-chaperone can also recruit the Hsp70 chaperone machinery, which upon ATP hydrolysis can unfold the "frozen" misfolded segment, thereby allowing it, upon release, to refold to the native state (Figure 5, middle path). In the specific case of type II J-co-chaperones (or $\Delta$ DnaJ), the unfolding action of DnaK may remain futile (Figure 5, upper path), unless a thioredoxin is supplemented.

Yet, under more extreme oxidative, $\Delta$ DnaJ of Type 2 J-proteins could also be slightly more effective J-cochaperones than Type 1 at mediating the unfolding of particularly sensitive proteins, such as heat-denatured G6PDH. This may be attributed to the presence of the eight reduced cysteines that can form dysfunctional disulfide bonds with the other proteins. Hence, under oxidative stress, the more resistant type II J-proteins, such as the E. coli CbpA or the human DNAJB1, may be more effective at assisting protein unfolding, than the oxygen-sensitive type I DnaJ or DNAJA1. Excessive sensitivity of type I J-proteins to oxidative conditions could explain their absence in the oxidative environment of the ER lumen and the presence of only cysteine-depleted type II and III J-proteins.

Protein misfolding and aggregation likely appeared in the course of evolution when small single domain proteins became complex and multi-domain (Netzer and Hartl, 1997), implying that the first molecular chaperone, such a DnaK and DnaJ,

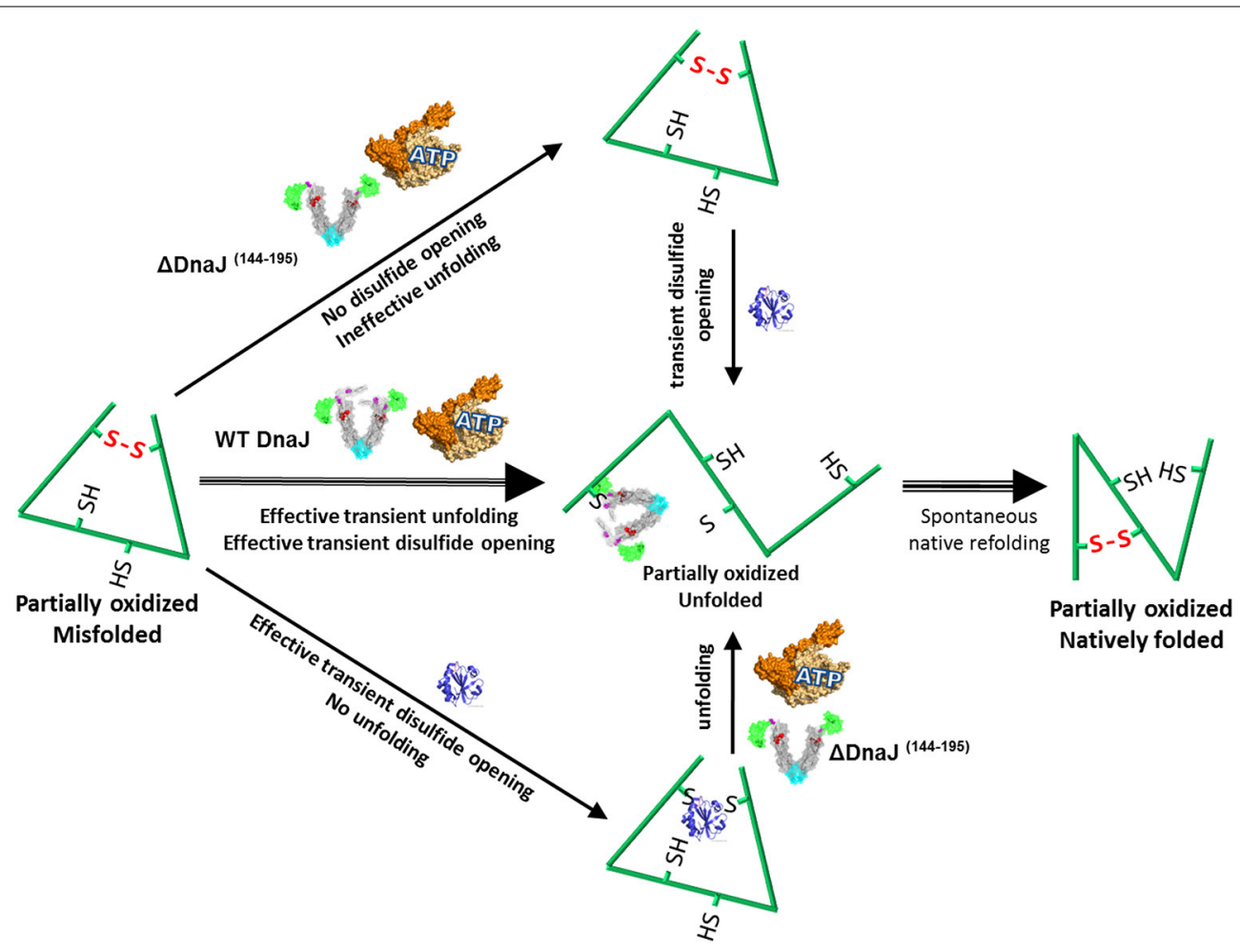

FIGURE 5 | Proposed model for the concerted dithiol-oxidoreductase and unfoldase activities by type I J-co-chaperones. Under mildly oxidative conditions, a stress-misfolded polypeptide may be stabilized both by misaligned disulfide bonds and by strong cooperative hydrophobic interactions, for example in wrong beta sheets. Wild type DnaJ can recruit DnaK to forcefully unfold wrong beta structures and at the same time catalyze the transient opening of wrong disulfide bonds. Thus a partially unfolded intermediate is produced, which can thereafter spontaneously refold to the native state (Strong middle arrows). In the presence of the $\Delta$ DnaJ, wrong disulfide bonds cannot be opened and DnaK remains ineffective at unfolding the wrong structures, unless thioredoxin is subsequently added (upper arrows). In the presence of thioredoxin, wrong disulfide bonds are transiently untied but there is no unfolding of wrong beta structures, unless $\Delta$ DnaJ, DnaK and ATP are subsequently added (lower arrows). 
likely evolved under a reducing atmosphere devoid of free oxygen (Gupta et al., 1989; Picketts et al., 1989; Ellis and van der Vies, 1991). It is tempting to speculate that in the earliest anoxic life forms, the first J-proteins were simple type II and only later, a BSD2-like thiol-disulfide oxidoreductase modular domain was added to form type I J-proteins to optimize the unfoldase action of Hsp70 under mild oxygen.

\section{THE POSSIBLE FUNCTION OF TYPE I AND II IN PROTEIN MISFOLDING DISEASES}

We performed a Genevestigator analysis of mRNA expression levels in human cells (Zimmermann et al., 2004) challenged by various stresses associated to oxidative stress and ROS production. Thus heat-shock, cigarette smoke, or chemical treatments with elesclomol or the HSP90-inhibitor geldanamycin, as well as in chronically challenged tissues in Parkinson's disease, type II, DNAJB1 and DNAJB4 were found to be systematically more overexpressed than type I, DNAJA1 and DNAJA2 (Supplementary Figure 3). This is possibly because extreme persistent oxidative and inflammation stress, as in cells of the substantia nigra during progression of Parkinson's disease, which are chronically challenged with toxic aggregates that compromise membranes integrity, the excessive ROS production might inactivate and crosslink the highly reactive catalytic cysteines in type I J-proteins and cause inactivation by intra- and inter-molecular crosslinks. Under such extreme oxidative conditions, it would be counterproductive for cells to overproduce type I co-chaperones and more advantageous to favor the production of ROS-resistant although less performing type-II cochaperones and possibly in collaboration with more appropriate Thioredoxins, such as BSD2, to effectively unfold otherwise oxidized misfolded polypeptides. Our results suggest that the specific upregulation in aging cells of type I J-proteins or Thioredoxins, in combination with Hsp110 and Hsc70 (Mattoo et al., 2013) could be of important therapeutic potential to combat ROS-mediated stress and inflammationinduced onset of proteotoxicity in degenerative diseases.

\section{ACKNOWLEDGMENTS}

We thank Anika Braune for technical assistance. This project was financed by Swiss National Science Foundation Grants 125502/1 and $140512 / 1$.

\section{SUPPLEMENTARY MATERIAL}

The Supplementary Material for this article can be found online at: http://www.frontiersin.org/journal/10.3389/fmolb.2014. 00007/abstract

\section{REFERENCES}

Anfinsen, C. B. (1973). Principles that govern the folding of protein chains. Science 181, 223-230. doi: 10.1126/science.181.4096.223

Arike, L., Valgepea, K., Peil, L., Nahku, R., Adamberg, K., and Vilu, R. (2012). Comparison and applications of label-free absolute proteome quantification methods on Escherichia coli. J. Proteomics 75, 5437-5448. doi: 10.1016/j.jprot.2012.06.020

Banecki, B., Liberek, K., Wall, D., Wawrzynow, A., Georgopoulos, C., Bertoli, E., et al. (1996). Structure-function analysis of the zinc finger region of the DnaJ molecular chaperone. J. Biol. Chem. 271, 14840-14848. doi: 10.1074/jbc.271.25.14840

Baneyx, F., and Nannenga, B. L. (2010). Chaperones: a story of thrift unfolds. Nat. Chem. Biol. 6, 880-881. doi: 10.1038/nchembio.468
Barends, T. R., Brosi, R. W., Steinmetz, A., Scherer, A., Hartmann, E., Eschenbach, J., et al. (2013). Combining crystallography and EPR: crystal and solution structures of the multidomain cochaperone DnaJ. Acta Crystallogr. D Biol. Crystallogr. 69(Pt 8), 1540-1552. doi: 10.1107/S0907444913010640

Ben-Zvi, A., De Los Rios, P., Dietler, G., and Goloubinoff, P. (2004). Active solubilization and refolding of stable protein aggregates by cooperative unfolding action of individual hsp70 chaperones. J. Biol. Chem. 279, 37298-37303. doi: 10.1074/jbc.M405627200

Bird, J. G., Sharma, S., Roshwalb, S. C., Hoskins, J. R., and Wickner, S. (2006) Functional analysis of CbpA, a DnaJ homolog and nucleoid-associated DNAbinding protein. J. Biol. Chem. 281, 34349-34356. doi: 10.1074/jbc.M603365200

Brutnell, T. P., Sawers, R. J., Mant, A., and Langdale, J. A. (1999). BUNDLE SHEATH DEFECTIVE2, a novel protein required for post-translational regulation of the rbcL gene of maize. Plant Cell 11, 849-864. doi: 10.1105/tpc.11.5.849

Bucciantini, M., Giannoni, E., Chiti, F., Baroni, F., Formigli, L., Zurdo, J., et al. (2002). Inherent toxicity of aggregates implies a common mechanism for protein misfolding diseases. Nature 416, 507-511. doi: 10.1038/416507a

Cabrita, L. D., Dobson, C. M., and Christodoulou, J. (2010). Protein folding on the ribosome. Curr. Opin. Struct. Biol. 20, 33-45. doi: 10.1016/j.sbi.2010.01.005

Collet, J. F., D’Souza, J. C., Jakob, U., and Bardwell, J. C. (2003). Thioredoxin 2, an oxidative stress-induced protein, contains a high affinity zinc binding site. J. Biol. Chem. 278, 45325-45332. doi: 10.1074/jbc.M307818200

Corpet, F. (1988). Multiple sequence alignment with hierarchical clustering. Nucleic Acids Res. 16, 10881-10890. doi: 10.1093/nar/16.22.10881

Creighton, T. E., and Goldenberg, D. P. (1984). Kinetic role of a meta-stable nativelike two-disulphide species in the folding transition of bovine pancreatic trypsin inhibitor. J. Mol. Biol. 179, 497-526. doi: 10.1016/0022-2836(84)90077-9

de Crouy-Chanel, A., Kohiyama, M., and Richarme, G. (1995). A novel function of Escherichia coli chaperone DnaJ. Protein-disulfide isomerase. J. Biol. Chem. 270, 22669-22672. doi: 10.1074/jbc.270.39.22669

De Los Rios, P., and Goloubinoff, P. (2012). Protein folding: chaperoning protein evolution. Nat. Chem. Biol. 8, 226-228. doi: 10.1038/nchembio.791

De Los Rios, P., Ben-Zvi, A., Slutsky, O., Azem, A., and Goloubinoff, P. (2006) Hsp70 chaperones accelerate protein translocation and the unfolding of stable protein aggregates by entropic pulling. Proc. Natl. Acad. Sci. U.S.A. 103, 6166-6171. doi: 10.1073/pnas.0510496103

Diamant, S., Ben-Zvi, A. P., Bukau, B., and Goloubinoff, P. (2000). Size-dependent disaggregation of stable protein aggregates by the DnaK chaperone machinery. J. Biol. Chem. 275, 21107-21113. doi: 10.1074/jbc.M001293200

Dobson, C. M. (2003). Protein folding and misfolding. Nature 426, 884-890. doi: 10.1038 /nature02261

Ellis, R. J. (2001). Macromolecular crowding: obvious but underappreciated. Trends Biochem. Sci. 26, 597-604. doi: 10.1016/S0968-0004(01)01938-7

Ellis, R. J., and van der Vies, S. M. (1991). Molecular chaperones. Annu. Rev. Biochem. 60, 321-347. doi: 10.1146/annurev.bi.60.070191.001541

Finka, A., and Goloubinoff, P. (2013). Proteomic data from human cell cultures refine mechanisms of chaperone-mediated protein homeostasis. Cell Stress Chaperones 18, 591-605. doi: 10.1007/s12192-013-0413-3

Finka, A., Mattoo, R. U., and Goloubinoff, P. (2011). Meta-analysis of heat- and chemically upregulated chaperone genes in plant and human cells. Cell Stress Chaperones 16, 15-31. doi: 10.1007/s12192-010-0216-8.

Gautschi, M., Lilie, H., Funfschilling, U., Mun, A., Ross, S., Lithgow, T., et al. (2001). RAC, a stable ribosome-associated complex in yeast formed by the DnaK-DnaJ homologs Sszlp and zuotin. Proc. Natl. Acad. Sci. U.S.A. 98, 3762-3767. Epub 2001/03/29. doi: 10.1073/pnas.071057198

Geiger, T., Wehner, A., Schaab, C., Cox, J., and Mann, M. (2012). Comparative proteomic analysis of eleven common cell lines reveals ubiquitous but varying expression of most proteins. Mol. Cell Proteom. 11:M111.014050. doi: 10.1074/ mcp.M111.014050

Gupta, R. S., Picketts, D. J., and Ahmad, S. (1989). A novel ubiquitous protein 'chaperonin' supports the endosymbiotic origin of mitochondrion and plant chloroplast. Biochem. Biophys. Res. Commun. 163, 780-787. doi: 10.1016/0006291X(89)92290-0

Gur, E., Biran, D., Shechter, N., Genevaux, P., Georgopoulos, C., and Ron, E. Z. (2004). The Escherichia coli DjlA and CbpA proteins can substitute for DnaJ in DnaK-mediated protein disaggregation. J. Bacteriol. 186, 7236-7242. doi: 10.1128/JB.186.21.7236-7242.2004

Hinault, M. P., Ben-Zvi, A., and Goloubinoff, P. (2006). Chaperones and proteases: cellular fold-controlling factors of proteins in neurodegenerative diseases and aging. J. Mol. Neurosci. 30, 249-265. doi: 10.1385/JMN:30:3:249 
Hinault, M. P., Farina-Henriquez-Cuendet, A., Mattoo, R. U., Mensi, M., Dietler, G., Lashuel, H. A., et al. (2010). Stable alpha-synuclein oligomers strongly inhibit chaperone activity of the Hsp70 system by weak interactions with J-domain co-chaperones. J. Biol. Chem. 285, 38173-38182. doi: 10.1074/jbc.M110.127753

Hinault, M. P., Farina-Henriquez-Cuendet, A., and Goloubinoff, P. (2011). Molecular chaperones and associated cellular clearance mechanisms against toxic protein conformers in Parkinson's disease. Neurodegener. Dis. 8, 397-412. doi: $10.1159 / 000324514$

Holmgren, A. (1979). Thioredoxin catalyzes the reduction of insulin disulfides by dithiothreitol and dihydrolipoamide. J. Biol. Chem. 254, 9627-9632.

Irvine, A. G., Wallis, A. K., Sanghera, N., Rowe, M. L., Ruddock, L. W., Howard, M. J., et al. (2014). Protein disulfide-isomerase interacts with a substrate protein at all stages along its folding pathway. PLoS ONE 9:e82511. doi: 10.1371/journal.pone.0082511

Jiang, J., Taylor, A. B., Prasad, K., Ishikawa-Brush, Y., Hart, P. J., Lafer, E. M., et al. (2003). Structure-function analysis of the auxilin J-domain reveals an extended Hsc70 interaction interface. Biochemistry 42, 5748-5753. doi: 10.1021/bi034270g

Kampinga, H. H., and Craig, E. A. (2010). The HSP70 chaperone machinery: J proteins as drivers of functional specificity. Nat. Rev. Mol. Cell Biol. 11, 579-592. doi: $10.1038 / \mathrm{nrm} 2941$

Kampinga, H. H., Hageman, J., Vos, M. J., Kubota, H., Tanguay, R. M., Bruford, E. A., et al. (2009). Guidelines for the nomenclature of the human heat shock proteins. Cell Stress Chaperones 14, 105-111. doi: 10.1007/s12192-008-0068-7

Kolberg, M., Strand, K. R., Graff, P., and Andersson, K. K. (2004). Structure, function, and mechanism of ribonucleotide reductases. Biochim. Biophys. Acta 1699, 1-34. doi: 10.1016/j.bbapap.2004.02.007

Linke, K., Wolfram, T., Bussemer, J., and Jakob, U. (2003). The roles of the two zinc binding sites in DnaJ. J. Biol. Chem. 278, 44457-44466. doi: 10.1074/jbc.M307491200

Ma, Y., Greener, T., Pacold, M. E., Kaushal, S., Greene, L. E., and Eisenberg, E. (2002). Identification of domain required for catalytic activity of auxilin in supporting clathrin uncoating by Hsc70. J. Biol. Chem. 277, 49267-49274. doi: 10.1074/jbc.M203695200

Martin, J., and Hartl, F. U. (1997). The effect of macromolecular crowding on chaperonin-mediated protein folding. Proc. Natl. Acad. Sci. U.S.A. 94, 1107-1112. doi: 10.1073/pnas.94.4.1107

Mattoo, R. U., and Goloubinoff, P. (2014). Molecular chaperones are nanomachines that catalytically unfold misfolded and alternatively folded proteins. Cell. Mol. Life Sci. doi: 10.1007/s00018-014-1627-y. [Epub ahead of print].

Mattoo, R. U., Sharma, S. K., Priya, S., Finka, A., and Goloubinoff, P. (2013). Hsp110 is a bona fide chaperone using ATP to unfold stable misfolded polypeptides and reciprocally collaborate with $\mathrm{Hsp} 70$ to solubilize protein aggregates. J. Biol. Chem. 288, 21399-21411. doi: 10.1074/jbc.M113.479253

McCarty, J. S., Rudiger, S., Schonfeld, H. J., Schneider-Mergener, J., Nakahigashi, K., Yura, T., et al. (1996). Regulatory region C of the E. coli heat shock transcription factor, sigma32, constitutes a DnaK binding site and is conserved among eubacteria. J. Mol. Biol. 256, 829-837. doi: 10.1006/jmbi.1996.0129

Mendoza, J. A., Rogers, E., Lorimer, G. H., and Horowitz, P. M. (1991). Chaperonins facilitate the in vitro folding of monomeric mitochondrial rhodanese. J. Biol. Chem. 266, 13044-13049.

Misselwitz, B., Staeck, O., Matlack, K. E., and Rapoport, T. A. (1999). Interaction of BiP with the J-domain of the Sec63p component of the endoplasmic reticulum protein translocation complex. J. Biol. Chem. 274, 20110-20115. doi: 10.1074/jbc.274.29.20110

Natalello, A., Mattoo, R. U., Priya, S., Sharma, S. K., Goloubinoff, P., and Doglia, S. M. (2013). Biophysical characterization of two different stable misfolded monomeric polypeptides that are chaperone-amenable substrates. J. Mol. Biol. 425, 1158-1171. doi: 10.1016/j.jmb.2012.12.025

Netzer, W. J., and Hartl, F. U. (1997). Recombination of protein domains facilitated by co-translational folding in eukaryotes. Nature 388, 343-349. doi: $10.1038 / 41024$.

Ou, W. B., Luo, W., Park, Y. D., and Zhou, H. M. (2001). Chaperone-like activity of peptidyl-prolyl cis-trans isomerase during creatine kinase refolding. Protein Sci. 10, 2346-2353. doi: 10.1110/ps.23301

Pais, J. E., Schilke, B., and Craig, E. A. (2011). Reevaluation of the role of the Pam18:Pam16 interaction in translocation of proteins by the mitochondrial Hsp70-based import motor. Mol. Biol. Cell 22, 4740-4749. doi: 10.1091/mbc.E11-08-0715
Parsell, D. A., Kowal, A. S., Singer, M. A., and Lindquist, S. (1994). Protein disaggregation mediated by heat-shock protein Hsp104. Nature 372, 475-478. doi: 10.1038/372475a0

Picketts, D. J., Mayanil, C. S., and Gupta, R. S. (1989). Molecular cloning of a Chinese hamster mitochondrial protein related to the "chaperonin" family of bacterial and plant proteins. J. Biol. Chem. 264, 12001-12008.

Priya, S., Sharma, S. K., and Goloubinoff, P. (2013a). Molecular chaperones as enzymes that catalytically unfold misfolded polypeptides. FEBS Lett. 587, 1981-1987. doi: 10.1016/j.febslet.2013.05.014

Priya, S., Sharma, S. K., Sood, V., Mattoo, R. U., Finka, A., Azem, A., et al. (2013b). GroEL and CCT are catalytic unfoldases mediating out-of-cage polypeptide refolding without ATP. Proc. Natl. Acad. Sci. U.S.A. 110, 7199-7204. doi: 10.1073/pnas.1219867110

Ramos, C. H., Oliveira, C. L., Fan, C. Y., Torriani, I. L., and Cyr, D. M. (2008). Conserved central domains control the quaternary structure of type I and type II Hsp40 molecular chaperones. J. Mol. Biol. 383, 155-166. doi: 10.1016/j.jmb.2008.08.019

Rampelt, H., Kirstein-Miles, J., Nillegoda, N. B., Chi, K., Scholz, S. R., Morimoto, R. I., et al. (2012). Metazoan Hsp70 machines use Hsp110 to power protein disaggregation. EMBO J. 31, 4221-4235. doi: 10.1038/emboj. 2012.264

Saaranen, M. J., and Ruddock, L. W. (2013). Disulfide bond formation in the cytoplasm. Antioxid. Redox Signal. 19, 46-53. doi: 10.1089/ars.2012.4868.

Schwaller, M., Wilkinson, B., and Gilbert, H. F. (2003). Reduction-reoxidation cycles contribute to catalysis of disulfide isomerization by proteindisulfide isomerase. J. Biol. Chem. 278, 7154-7159. doi: 10.1074/jbc.M2110 36200

Selkoe, D. J. (2004). Cell biology of protein misfolding: the examples of Alzheimer's and Parkinson's diseases. Nat. Cell. Biol. 6, 1054-1061. doi: 10.1038/ncb11041054

Sharma, S. K., De Los Rios, P., Christen, P., Lustig, A., and Goloubinoff, P. (2010). The kinetic parameters and energy cost of the Hsp70 chaperone as a polypeptide unfoldase. Nat. Chem. Biol. 6, 914-920. doi: 10.1038/nchembio.455

Shorter, J. (2011). The mammalian disaggregase machinery: Hsp110 synergizes with Hsp70 and Hsp40 to catalyze protein disaggregation and reactivation in a cell-free system. PLoS ONE 6:e26319. doi: 10.1371/journal.pone.0026319

Thomas, J. A., and Mallis, R. J. (2001). Aging and oxidation of reactive protein sulfhydryls. Exp. Gerontol. 36, 1519-1526.

Ueguchi, C., Kakeda, M., Yamada, H., and Mizuno, T. (1994). An analogue of the DnaJ molecular chaperone in Escherichia coli. Proc. Natl. Acad. Sci. U.S.A. 91, 1054-1058. doi: 10.1073/pnas.91.3.1054

Wall, D., Zylicz, M., and Georgopoulos, C. (1994). The NH2-terminal 108 amino acids of the Escherichia coli DnaJ protein stimulate the ATPase activity of DnaK and are sufficient for lambda replication. J. Biol. Chem. 269, 5446-5451.

Ye, J., Cho, S. H., Fuselier, J., Li, W., Beckwith, J., and Rapoport, T. A. (2007). Crystal structure of an unusual thioredoxin protein with a zinc finger domain. J. Biol. Chem. 282, 34945-34951. doi: 10.1074/jbc.M704044200

Zimmermann, P., Hirsch-Hoffmann, M., Hennig, L., and Gruissem, W. (2004). GENEVESTIGATOR. Arabidopsis microarray database and analysis toolbox. Plant Physiol. 136, 2621-2632. doi: 10.1104/pp.104.046367

Conflict of Interest Statement: The authors declare that the research was conducted in the absence of any commercial or financial relationships that could be construed as a potential conflict of interest.

Received: 21 May 2014; accepted: 13 July 2014; published online: 31 July 2014.

Citation: Mattoo RUH, Farina Henriquez Cuendet A, Subanna S, Finka A, Priya S, Sharma SK and Goloubinoff $P$ (2014) Synergism between a foldase and an unfoldase: reciprocal dependence between the thioredoxin-like activity of DnaJ and the polypeptide-unfolding activity of DnaK. Front. Mol. Biosci. 1:7. doi: 10.3389/fmolb. 2014.00007

This article was submitted to Protein Folding, Misfolding and Degradation, a section of the journal Frontiers in Molecular Biosciences.

Copyright (C) 2014 Mattoo, Farina Henriquez Cuendet, Subanna, Finka, Priya, Sharma and Goloubinoff. This is an open-access article distributed under the terms of the Creative Commons Attribution License (CC BY). The use, distribution or reproduction in other forums is permitted, provided the original author(s) or licensor are credited and that the original publication in this journal is cited, in accordance with accepted academic practice. No use, distribution or reproduction is permitted which does not comply with these terms. 